\title{
Epigenetic aspects of MDS and its molecular targeted therapy
}

\author{
Jumpei Yamazaki · Jean-Pierre J. Issa
}

Received: 6 August 2012/Revised: 19 September 2012/Accepted: 25 September 2012/Published online: 10 October 2012

(c) The Japanese Society of Hematology 2012

\begin{abstract}
The term "epigenetics" refers to clonally inherited stable variability in gene expression without underlying genetic changes. There are two well-known molecular mechanisms for epigenetic information: DNA methylation and histone modifications. Epigenetic changes have been recognized in the past decade as critical factors for physiological phenomena such as embryogenesis and the differentiation of normal cells. There is recent interest regarding the involvement of aberrant DNA methylation and histone modifications in mediating altered physiology in cancer. MDS is characterized by epigenetic changes, mutations in epigenetic regulators, and response to DNA methylation inhibitors, suggesting that epigenetic changes are unique features of MDS patients. In this article, recent progress in the understanding of MDS epigenetics and epigenetics-based therapies is reviewed.
\end{abstract}

Keywords Epigenetics - DNA methylation - Histone modification · MDS · Mutation

\section{Epigenetics}

Epigenetic changes, heritable through mitosis, lead to variability in gene expression without affecting the genetic sequence. These epigenetic processes play an important role in the early stages of natural development, from

J. Yamazaki $(\bowtie) \cdot$ J.-P. J. Issa

Fels Institute for Cancer Research and Molecular Biology,

Temple University, Philadelphia, PA 19140, USA

e-mail: jumpei.yamazaki@temple.edu

J. Yamazaki · J.-P. J. Issa

Department of Leukemia, The University of Texas MD

Anderson Cancer Center, Houston, TX 77030, USA embryogenesis to the determination of cellular fate for commitment to their lineage [1]. Epigenetics process can also result in biological diversity and phenotypic variation. Given that cancers are considered to have variable phenotypes, it has been appreciated that dysregulated epigenetic mechanisms can be a fundamental mechanism in cancer, and targeted therapy for these processes is of clinical interest $[2,3]$. Besides DNA methylation, which is the most studied epigenetic mechanism in cancer, posttranslational histone modifications have also been found to mediate epigenetics (Fig. 1).

DNA methylation is the addition of a methyl group to cytosines at the $5^{\prime}$ position of a $\mathrm{CpG}$ dinucleotide by a covalent modification which results in the formation of 5-methylcytosine $(5 \mathrm{mC})$, a base that changes the interactions between protein(s) and DNA. In mammalian cells, DNA methylation is a replication-dependent reaction catalyzed by DNA methyltransferases (DNMTs) which are present at the replication fork during the S-phase [4]. CpG dinucleotides are typically rare and scattered throughout the genome and are fully methylated. However, DNA methylation also involves CpGrich regions called "CpG islands" (CGIs) [5]. These have been shown to be present in approximately half of the human gene promoters. CGI methylation is associated with absent transcription from the involved promoter, such as that shown in the inactive $\mathrm{X}$ chromosome in women [6] and in imprinting $[7,8]$. The mechanism whereby CGI methylation suppresses gene transcription has been partially elucidated in vitro [9]. DNA methylation leads to silencing directly, by the inhibition of transcription factor binding, as well as indirectly, by the recruitment of methyl-binding domain proteins such as $\mathrm{MeCp} 2$. MeCp2 binding is followed by the recruitment of a repressor protein complex which includes histone deacetylases (HDACs), and eventually leads to a closed chromatin configuration and gene silencing [10]. 


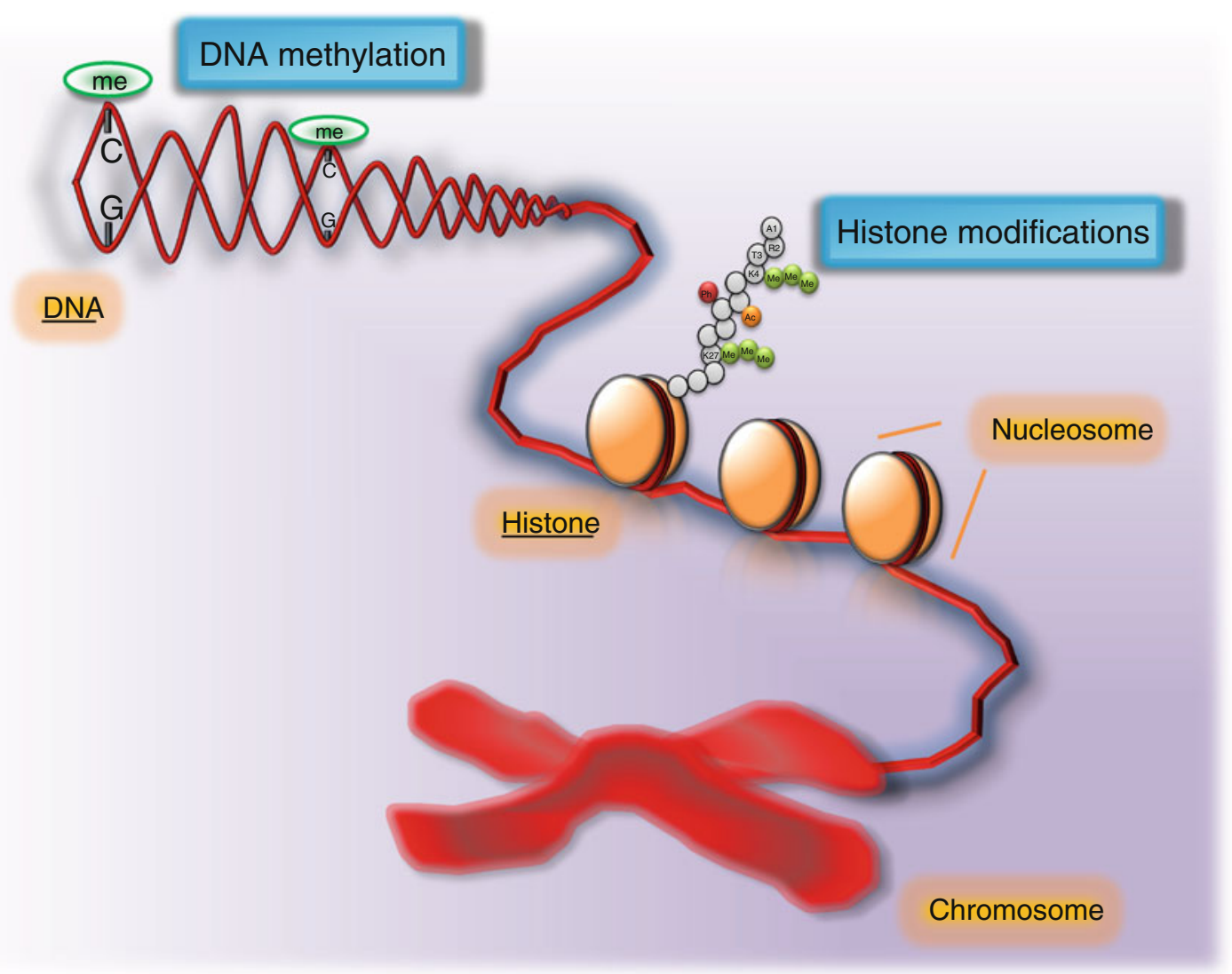

Fig. 1 DNA methylation and histone modification. DNA methylation (green oval) occurs at the cytosines of a $\mathrm{CpG}$ dinucleotide, resulting in the formation of 5-methylcytosine $(5 \mathrm{mC})$. Histones are small

Recently, the TET protein family members TET1, TET2, and TET3 have been found to convert $5 \mathrm{mC}$ into 5 -hydroxymethylcytosine $(5 \mathrm{hmC})$ [11, 12]. Further oxidation to $5 \mathrm{hmC}$ could also occur, resulting in the generation of the oxidation derivatives 5-formylcytosine and 5-carboxylcytosine [13]. Although the biological significance of these derivatives remains to be fully understood, they likely play an essential role in active demethylation. TET proteins show tissue-specific differential expression, with TET1 being mainly expressed in embryonic stem cells, whereas TET2 and TET3 are more ubiquitously expressed [14]. Interestingly, TET2 has been found to be mutated in myeloid malignancies including MDS (discussed later).

Histones are small proteins which wrap around DNA to form nucleosomes. Each nucleosome consists of eight histone molecules (two each of $\mathrm{H} 2 \mathrm{~A}, \mathrm{H} 2 \mathrm{~B}, \mathrm{H} 3$, and $\mathrm{H} 4$ ) [15]. Among these histone molecules, $\mathrm{H} 3$ and $\mathrm{H} 4$ have been well studied and are considered to be key regulators of chromatin configuration, adding post-translational modifications including methylation, acetylation, phosphorylation, ubiquitination, and sumoylation to their $\mathrm{N}$-terminal tails which protrude outside the basic nucleosomal structure [16-18]. Specific modifications to the proteins which DNA wrap around to form nucleosomes. Specific modifications (denoted by small green, orange, and red circles) to the amino acids (denoted by gray circles) of these histones' tails occur

amino acids in these histone tails occur, resulting in changes to the chromatin configuration. These changes serve either to promote or silence transcription, depending upon the specific amino acid(s) affected. Of these modifications, methylation and acetylation of specific lysine residues on $\mathrm{H} 3$ and $\mathrm{H} 4$ are the most studied [19]. Several enzymes have been identified which catalyze the modifications: histone acetyltransferases (HATs), HDACs, histone methyltransferases (HMTs), and histone demethylases (HDMTs). These enzymes work in concert with transcriptional activator/repressor complexes to target specific gene promoters.

\section{Epigenetic changes in cancer}

There are two aspects to changes in DNA methylation in cancer. For the most part, these changes involve simultaneous global demethylation and de novo gain of methylation at unmethylated CGIs [20]. Global DNA hypomethylation was first inferred from the measurement of global $5 \mathrm{mC}$ content and is now considered to be a common feature in cancer [21]. In various cancers, loss of 
$5 \mathrm{mC}$ content was found to reach an average of $10 \%$ [22], and affected repetitive elements and specific gene promoters [23, 24]. Although the cause of this demethylation remains unclear, marked loss of $5 \mathrm{mC}$ was shown to be associated with chromosomal breaks, genomic instabilities, increased mutation rates, and reactivation of normally silenced genes [23, 25]. Alongside global DNA hypomethylation, many genes have been shown to demonstrate de novo DNA methylation, especially at their promoters [2]. As mentioned above, the fact that these events are linked to the silencing of gene expression leads to the hypothesis that de novo DNA methylation is an alternate way of silencing tumor suppressor genes. Evidence has been shown for CGI methylation and its tumorigenic ability in genes such as $R B 1, p 16, V H L$, and $M L H 1$ [26], suggesting a selective advantage by apoptotic deficiency and unlimited proliferation, which tumor cells can obtain as a consequence of these methylation events.

Little is known about the patterns of histone modification disruption in human tumors. Recent studies have shown a global loss of $\mathrm{H} 4$ lysine 16 monoacetylation and H4 lysine 20 trimethylation in cancer [27]. These modifications were found to occur throughout the genome, specifically overlapping with areas of DNA hypomethylation in repetitive sequences. Conversely, loss of H3 lysine 9 acetylation and lysine 4 dimethylation or trimethylation and gain of $\mathrm{H} 3$ lysine 9 dimethylation or trimethylation and lysine 27 trimethylation were found at specific gene promoters, and can contribute to tumorigenesis by silencing critical tumor suppressor genes [28].

A recent interesting observation is the correlation between DNA methylation and histone modification. A certain group of genes has been found to be marked by the repressive polycomb group $(\mathrm{PcG})$ of proteins, which are complexes responsible for $\mathrm{H} 3 \mathrm{~K} 27$ trimethylation in embryonic stem cells, and further marked by DNA methylation in cancer [29, 30]. These two groups appear to overlap, implying that certain genes are "poised" for silencing and "predetermined" to be the target of specific repressive histone marks in cancer.

It has also become apparent that histone modifications are misregulated due to genes genetically altered in cancer [31]. Direct evidence of this misregulation comes from the fact that several histone-modifying enzymes are molecularly altered in cancer. For example, $M L L$-an H3 lysine 4 methylase - is rearranged in a significant portion of acute leukemias [32], and $E Z H 2$ - an H3 lysine 27 methylase-is overexpressed or mutated in various malignancies [33, 34]. Interestingly, UTX, which catalyzes H3 lysine 27 demethylation, has also been identified as mutated in several types of cancers [35]. This suggests that shifting the balance of histone modifications is one of the important features of the alteration of gene expression in cancer by dysregulated histone modifiers. Dysregulations in gene expression could also occur via the recruitment of histone-modifying enzymes affected by altered genes in cancer. For example, the chimeric oncoprotein PML-PAR $\alpha$ in acute promyelocytic leukemia is shown to target specific promoters through the aberrant recruitment of HDACs and HMTs, which leads to silencing of gene expression [36]. Recently, recurrent somatic mutations were found in genes encoding histone proteins in pediatric glioblastomas [37, 38]. These mutations result in amino acid substitutions at two critical residues in the tail of $\mathrm{H} 3$ : lysine 27 and glycine 34, which likely results in a significant impact on chromatin structure.

\section{Epigenetic changes in MDS}

The fact that the phenotypic diversity of MDS cannot be fully explained by the recurrent aberrant karyotypes, which are well studied and used for their classification, has emphasized the importance of searching for other mechanisms responsible for this disease. Although detailed studies of histone modifications in MDS remain to be described, studies of DNA methylation in MDS have been intensively performed. A series of single locus studies have demonstrated that several genes are silenced in association with the methylation of their promoter in MDS. These include genes involved in cell-cycle regulation, apoptosis, adhesion and motility, and other pathways [26]. Among these, $C D K N 2 B$ (p15) methylation is frequently reported in therapy-related chronic myelomonocytic leukemia, refractory anemia with excess blasts in transformation, or AML arising from MDS [39, 40]. CDKN2B methylation in MDS is also associated with old age, deletions of $5 \mathrm{q}$ and $7 \mathrm{q}$, and a poor prognosis [41]. Roughly $50 \%$ of MDS patients show silenced gene expression due to hypermethylation of $C D K N 2 B$ at its promoter [42]. Interestingly, hypermethylation was found in rates which started at $0 \%$ in low-risk MDS, increased to $30 \%$ in high-risk MDS, and reached $75 \%$ in AML transformed from MDS [40]. In a recent study focusing on quantitative analysis of the DNA methylation status of ten selected genes [43], a hypermethylator phenotype of CGIs was identified that marks a subset of cases with MDS which often show concordant hypermethylation of several genes. This phenomenon, called $\mathrm{CpG}$ island methylator phenotype (CIMP), was first described in colon cancer [44] and later in glioma [45]. It results in the simultaneous inactivation of several genes by an unknown mechanism. In MDS, CIMP is associated with rapid progression to AML and shortened overall survival and progression-free survival [43]. This explains in part why the methylation of so many genes is reported as prognostic in MDS [26]: all these studies of individual genes are likely a common subset of cases affected by CIMP. Importantly, 


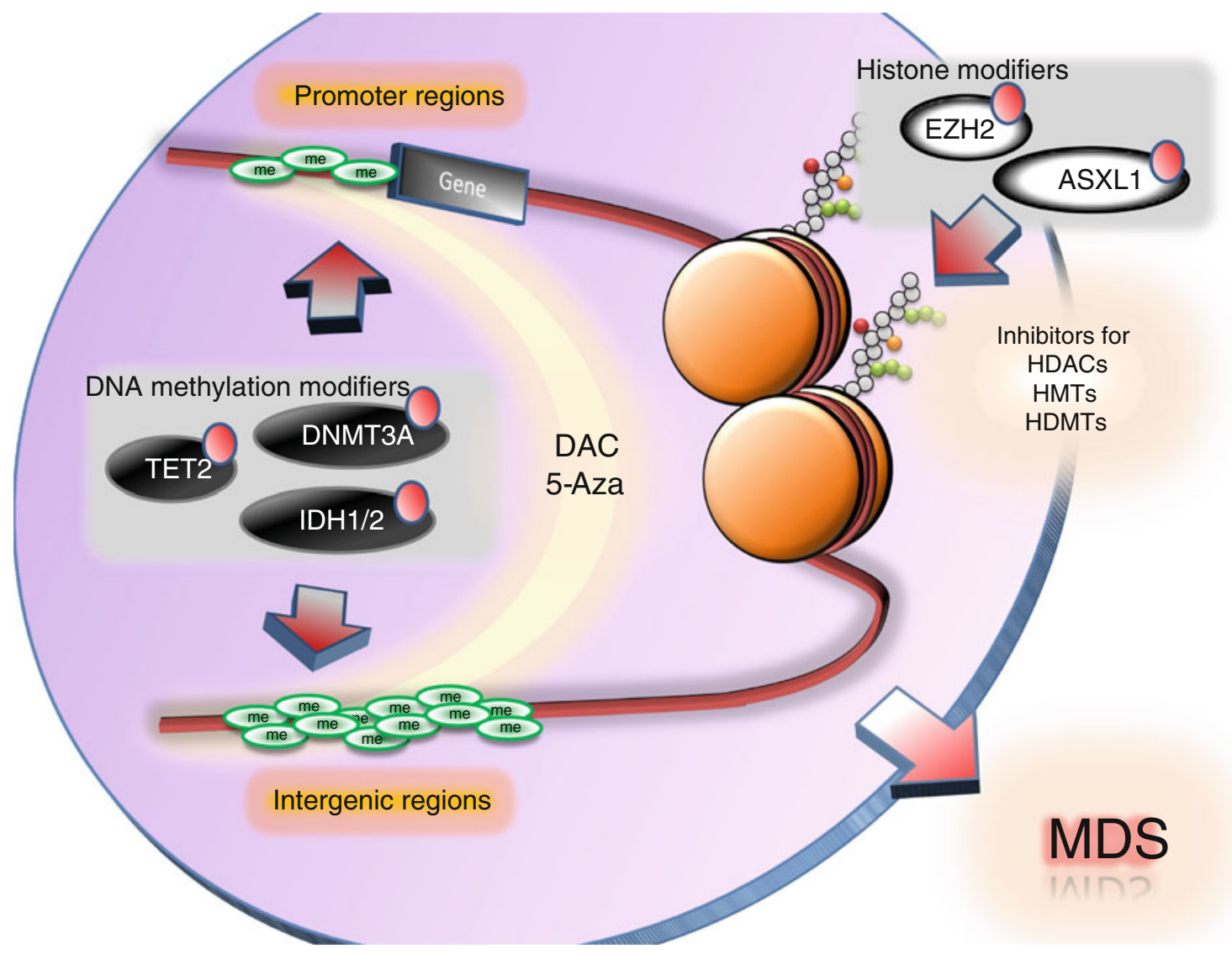

Fig. 2 Mutations of epigenetic regulators and possible targeted therapies. Various mutations have been identified in the genes of epigenetic regulators. These mutations are assumed to confer growth advantages to cells, resulting in MDS by affecting DNA methylation

some of these genes clearly have minimal functional impact on MDS, because they are not expressed in normal hematopoietic cells.

Genome-wide studies of DNA methylation have revealed that hundreds of genes are frequently hypermethylated in MDS, including genes of the WNT signaling pathway and MAP kinase pathway [46]. It has also been suggested that aberrant DNA methylation occurs more frequently than chromosome lesions in MDS [47]. As indicated by studies of individual genes, hypermethylation across the genome is associated with poor prognostic features and transformation to AML, independent of chromosomal aberration. There was a distinct methylation pattern in MDS and related AMLs in comparison to de novo AML, pointing to distinct pathogenic mechanisms [46]. As a result, DNA methylation is considered to be abnormal early on in MDS, and progression of the disease is associated with the accumulation of additional epigenetic events. These observations, taken together with the fact that DNA methylation is a reversible process, provide a rationale for the use of DNA methylation inhibitors in the treatment of MDS (discussed later). (in promoter and intergenic regions) and histone modification. DAC and AZA inhibit these effects on DNA methylation, whereas inhibitors for HDACs, HMTs, and HDMTs work on histone modification for the treatment of MDS

Compared to hypermethylation, global hypomethylation in MDS is less well understood. LINE-1 was used as a surrogate marker for global DNA methylation, and it was found to be increased in MDS [48] as opposed to solid tumors where decreases are often seen [23]. Using a promoter-array for methylation analysis, a smaller number of hypomethylation sites was observed compared to hypermethylation sites in MDS [46]. A recent report showed frequent promoter hypomethylation in TET2 mutant CMML cases [49], though this was not consistently found in other studies [50]. Extensive genome-wide analysis will be required to study global hypomethylation in MDS occurs to the same extent as in the other cancers.

Recent advances in technologies such as high-resolution SNP array and next-generation sequencing have led to important new findings in MDS. Various mutations have been identified in the genes that code for epigenetic regulators, including ASXL1, DNMT3A, EZH2, IDH1/2, and TET2 [51] (Fig. 2; Table 1). Although it is not yet fully understood whether MDS cases with mutations in these genes have characteristic epigenetic patterns, these findings suggest that epigenetic dysregulation has strong 
Table 1 Mutations in epigenetic regulators in MDS

\begin{tabular}{lcll}
\hline Gene & Frequency & Function & References \\
\hline TET2 & $20 \%$ in & Conversion of $5 \mathrm{mC}$ to & {$[52,82]$} \\
& MDS & 5 hmC & \\
& $30-50 \%$ in & & \\
& CMML & & \\
IDH1/2 & $<10 \%$ in & Conversion of isocitrate to & {$[83]$} \\
& MDS & $\alpha$ KG & \\
& \multicolumn{4}{c}{ Mutants generate 2HG } \\
DNMT3A & $<10 \%$ in & De novo DNA \\
& MDS & methyltransferase & {$[84]$} \\
ASXL1 & $10-20 \%$ in & Interaction with histone & {$[85,86]$} \\
& MDS & modifiers & \\
& $>40 \%$ in & \\
& CMML & & \\
EZH2 & $<10 \%$ in & Histone methyltransferase & {$[86]$} \\
& MDS & (H3K27me3) & \\
\hline
\end{tabular}

implications in this disease. TET2 is one well-studied gene in this regard. The incidence of TET2 gene alterations ranges from 10 to $25 \%$ in myeloid malignancies, with the highest frequency of mutation found in CMML, where TET2 mutations are noted in $35-50 \%$ of cases [52-54]. As reported for TET1 [12], TET2 also converts $5 \mathrm{mC}$ to $5 \mathrm{hmC}$ [11] in embryonic stem cells, and thus mutations of TET2 were theorized to contribute to leukemogenesis and to the disruption of hematopoietic differentiation by altering the epigenetic regulation of transcription via DNA methylation $[49,55]$. Furthermore, in murine models, TET2 deficiency impairs hematopoietic differentiation with the expansion of myeloid precursors $[56,57]$. The exact mechanism and the extent to which TET2 mutations affect DNA methylation remain in question. Ko et al. [49] reported a subset of genes with hypomethylation in CMML patients with TET2 mutations. However, our data recently suggested that effects of TET2 mutations on DNA methylation are primarily outside both CGI and promoters ([50] and in submission). These findings may provide further understanding of CMML leukemogenesis and could lead to the development of new strategies for CMML patients.

\section{Epigenetic therapy}

Epigenetic therapy refers to the treatment of cancer by targeting epigenetic pathways [58]. The principal idea of this approach is to pharmacologically relieve the effects of DNA methylation and chromatin remodeling on silenced genes in malignant cells. There are two classes of drugs that modify epigenetics which have been approved by the US Food and Drug Administration (FDA) for the treatment of cancer: DNA methylation inhibitors and HDAC inhibitors (HDIs).

Two cytosine analogs were first developed as cytotoxic agents in 1960s, found to induce peculiar differentiation phenotypes in vivo in 1970s, and shown in the early 1980s to be potent DNA methylation inhibitors [59]. The DNA hypomethylating property is limited to cytosine analogs with the shared structure of $5^{\prime}$ modifications of the ring. This property has been studied in two main analogs, 5-azacytidine (azacitidine, or AZA) and 5-aza-2'-deoxycytidine (decitabine, or DAC), because of their ability to incorporate into DNA and trap DNMTs through an irreversible covalent bond, leading to degradation of these enzymes [60]. Hypomethylation occurs in the cells proliferating after DNA synthesis in the absence of these enzymes, leading to hypomethylation in the daughter cells.

AZA incorporates into RNA, or incorporates into DNA after intracellular conversion to DAC and subsequently inhibits DNA methylation. Unlike AZA, DAC does not incorporate into RNA and is directly incorporated into DNA [61]. These drugs were found to be more effective in hematologic malignancies than in solid tumors, but are also quite toxic [62]. Interestingly, they only work as epigenetic modifiers when given at low doses. High doses inhibit DNA synthesis, which precedes their DNA hypomethylating effect. Recent work suggests that low doses of these agents hold the key to therapeutic benefits even in epithelial tumors [63]. One might easily imagine that initial studies of these drugs failed because of their unusual dose-response properties. However, AZA and DAC re-emerged after evidence of their effectiveness in the treatment of older patients at low dose was found $[64,65]$. Both AZA and DAC were tested later in relatively large studies at low to moderate doses and over multiple cycles of administration, thus optimizing their epigenetic modulation potential. Following promising phase II studies, AZA was tested in two separate phase III studies $[66,67]$ in MDS. Response rates ranging from 30 to $60 \%$ were observed, with improved survival as compared to either supportive care or cytotoxic chemotherapy. DAC also had promising early studies in MDS, and phase II studies confirmed responses ( $40 \%$ complete response; over $70 \%$ total response) and substantial effects on survival $[68,69]$. While there is relatively little data regarding their use in low-risk MDS, these two agents have been a major breakthrough and have become the standard of care for high-risk MDS, though a direct comparison between the two agents is not available.

One of the peculiar characteristics of epigenetic therapies is that the patterns of response are quite different from traditional cytotoxic therapies in MDS. In contrast to chemotherapy (which induces rapid response in MDS), a remarkable response induced by AZA and DAC is rare after one cycle, but is improved over time $[66,67]$ and with continued therapy [70]. Hypomethylating agents show 
mainly reversible side-effects on myelosuppression rather than the usual cytotoxic side-effects (mucositis, hair loss, diarrhea, renal failure, etc.). Most importantly, hypomethylating agents seemed to show better results when compared with traditional chemotherapy [67, 69], even lowdose chemotherapy. Furthermore, combinations of these drug and conventional chemotherapy have also been of clinical interest, since there are encouraging results in AML [71], and some potential in MDS [72]. Several studies are currently ongoing to obtain improved efficacies of these drugs, including the development of oral preparations [73] and small molecules that can inhibit DNMTs without requiring DNA incorporation [74].

The inhibition of histone-modifying enzymes will be another potential epigenetic target for MDS therapy. There are HDIs currently in clinical trials; however, less data is available for their use in MDS, though anecdotal responses have been reported [75]. Recently, it has also been reported that DNA methylation per se is not a permanent lock for silencing gene expression, but rather a combination of DNA methylation inhibitors with other drugs (such as HDIs) can be used to reactivate gene expression [76, 77]. Furthermore, there is increasing evidence that such combinations have encouraging results $[78,79]$. Therefore, it is likely that the rational design of combinations of several drugs targeting epigenetic pathways will be required for the treatment of MDS (Fig. 2). There is also a particular interest in developing drugs that can inhibit the activity of other epigenetic pathways, such as HMTs [80, 81], because these could work independently of (and could complement) DNA methylation inhibitors and HDIs. Given that mutations in several epigenetic regulators have been identified, it will be interesting to see if patients with different statuses for these mutations show different responses to epigenetic therapies.

\section{Conclusion}

There is increasing evidence that epigenetic mechanisms have been associated with gene expression variability in MDS. In addition to chromosomal aberrations, epigenetic aberrations have been found to play an important role in establishing the heterogeneous phenotype of MDS. Recent findings from genome-wide studies have revealed several mutations in epigenetic regulator genes and peculiar patterns in epigenetic status, emphasizing the importance of understanding the underlying epigenetic mechanisms of this disease. Further investigation will help provide new insight into the classification, prognosis, and treatment of MDS.

Acknowledgments The authors thank Jenna Al-Malawi for excellent editing of the manuscript. Work in the author's lab is supported by the
National Institutes of Health Grants CA100632, CA121104, and CA046939 and by a Stand Up to Cancer Grant from the American Association for Cancer Research. JPI is an American Cancer Society Clinical Research professor supported by a generous gift from the F. M. Kirby Foundation.

\section{References}

1. Jones PA, Baylin SB. The epigenomics of cancer. Cell. 2007; 128(4):683-92.

2. Baylin SB, Herman JG, Graff JR, Vertino PM, Issa JP. Alterations in DNA methylation: a fundamental aspect of neoplasia. Adv Cancer Res. 1998;72:141-96.

3. Jones PA, Laird PW. Cancer epigenetics comes of age. Nat Genet. 1999;21(2):163-7.

4. Klose RJ, Bird AP. Genomic DNA methylation: the mark and its mediators. Trends Biochem Sci. 2006;31(2):89-97.

5. Illingworth RS, Bird AP. CpG islands-'a rough guide'. FEBS Lett. 2009;583(11):1713-20.

6. Heard E, Clerc P, Avner P. X-chromosome inactivation in mammals. Annu Rev Genet. 1997;31:571-610.

7. Barlow DP. Gametic imprinting in mammals. Science. 1995;270(5242):1610-3.

8. Ferguson-Smith AC. Genomic imprinting: the emergence of an epigenetic paradigm. Nat Rev Genet. 2011;12(8):565-75.

9. Jones PL, Wolffe AP. Relationships between chromatin organization and DNA methylation in determining gene expression. Semin Cancer Biol. 1999;9(5):339-47.

10. Nan X, Ng HH, Johnson CA, Laherty CD, Turner BM, Eisenman $\mathrm{RN}$, et al. Transcriptional repression by the methyl-CpG-binding protein $\mathrm{MeCP} 2$ involves a histone deacetylase complex. Nature. 1998;393(6683):386-9.

11. Ito S, D'Alessio AC, Taranova OV, Hong K, Sowers LC, Zhang Y. Role of Tet proteins in $5 \mathrm{mC}$ to $5 \mathrm{hmC}$ conversion, ES-cell selfrenewal and inner cell mass specification. Nature. 2010;466 (7310):1129-33.

12. Tahiliani M, Koh KP, Shen Y, Pastor WA, Bandukwala H, Brudno $\mathrm{Y}$, et al. Conversion of 5-methylcytosine to 5-hydroxymethylcytosine in mammalian DNA by MLL partner TET1. Science. 2009;324(5929):930-5.

13. Ito S, Shen L, Dai Q, Wu SC, Collins LB, Swenberg JA, et al. Tet proteins can convert 5-methylcytosine to 5-formylcytosine and 5-carboxylcytosine. Science. 2011;333(6047):1300-3.

14. Nestor CE, Ottaviano R, Reddington J, Sproul D, Reinhardt D, Dunican D, et al. Tissue type is a major modifier of the 5-hydroxymethylcytosine content of human genes. Genome Res. 2012;22(3):467-77.

15. Khorasanizadeh $\mathrm{S}$. The nucleosome: from genomic organization to genomic regulation. Cell. 2004;116(2):259-72.

16. Strahl BD, Allis CD. The language of covalent histone modifications. Nature. 2000;403(6765):41-5.

17. Lachner $M$, Jenuwein $T$. The many faces of histone lysine methylation. Curr Opin Cell Biol. 2002;14(3):286-98.

18. Jenuwein T, Allis CD. Translating the histone code. Science. 2001;293(5532):1074-80.

19. Rice JC, Allis CD. Histone methylation versus histone acetylation: new insights into epigenetic regulation. Curr Opin Cell Biol. 2001;13(3):263-73.

20. Taby R, Issa JP. Cancer epigenetics. CA Cancer J Clin. 2010;60(6):376-92.

21. Feinberg AP, Vogelstein B. Hypomethylation distinguishes genes of some human cancers from their normal counterparts. Nature. 1983;301(5895):89-92. 
22. Feinberg AP, Gehrke CW, Kuo KC, Ehrlich M. Reduced genomic 5-methylcytosine content in human colonic neoplasia. Cancer Res. 1988;48(5):1159-61.

23. Estecio MR, Gharibyan V, Shen L, Ibrahim AE, Doshi K, He R, et al. LINE-1 hypomethylation in cancer is highly variable and inversely correlated with microsatellite instability. PLoS ONE. 2007;2(5):e399.

24. Dunn BK. Hypomethylation: one side of a larger picture. Ann N Y Acad Sci. 2003;983:28-42.

25. Chen RZ, Pettersson U, Beard C, Jackson-Grusby L, Jaenisch R. DNA hypomethylation leads to elevated mutation rates. Nature. 1998;395(6697):89-93.

26. Issa JP. Epigenetic changes in the myelodysplastic syndrome. Hematol Oncol Clin N Am. 2010;24(2):317-30.

27. Fraga MF, Ballestar E, Villar-Garea A, Boix-Chornet M, Espada J, Schotta G, et al. Loss of acetylation at Lys16 and trimethylation at Lys 20 of histone $\mathrm{H} 4$ is a common hallmark of human cancer. Nat Genet. 2005;37(4):391-400.

28. Esteller M. Cancer epigenomics: DNA methylomes and histonemodification maps. Nat Rev Genet. 2007;8(4):286-98.

29. Widschwendter M, Fiegl H, Egle D, Mueller-Holzner E, Spizzo G, Marth C, et al. Epigenetic stem cell signature in cancer. Nat Genet. 2007;39(2):157-8

30. Ohm JE, McGarvey KM, Yu X, Cheng L, Schuebel KE, Cope L, et al. A stem cell-like chromatin pattern may predispose tumor suppressor genes to DNA hypermethylation and heritable silencing. Nat Genet. 2007;39(2):237-42.

31. Chi P, Allis CD, Wang GG. Covalent histone modificationsmiswritten, misinterpreted and mis-erased in human cancers. Nat Rev Cancer. 2010;10(7):457-69.

32. Armstrong SA, Golub TR, Korsmeyer SJ. MLL-rearranged leukemias: insights from gene expression profiling. Semin Hematol. 2003;40(4):268-73.

33. Varambally S, Dhanasekaran SM, Zhou M, Barrette TR, KumarSinha C, Sanda MG, et al. The polycomb group protein EZH2 is involved in progression of prostate cancer. Nature. 2002;419(6907):624-9.

34. Kondo Y, Shen L, Cheng AS, Ahmed S, Boumber Y, Charo C, et al. Gene silencing in cancer by histone H3 lysine 27 trimethylation independent of promoter DNA methylation. Nat Genet. 2008;40(6):741-50.

35. van Haaften G, Dalgliesh GL, Davies H, Chen L, Bignell G, Greenman C, et al. Somatic mutations of the histone H3K27 demethylase gene UTX in human cancer. Nat Genet. 2009;41(5):521-3.

36. Mistry AR, Pedersen EW, Solomon E, Grimwade D. The molecular pathogenesis of acute promyelocytic leukaemia: implications for the clinical management of the disease. Blood Rev. 2003;17(2):71-97.

37. Schwartzentruber J, Korshunov A, Liu XY, Jones DT, Pfaff E, Jacob K, et al. Driver mutations in histone H3.3 and chromatin remodelling genes in paediatric glioblastoma. Nature. 2012;482(7384):226-31.

38. Wu G, Broniscer A, McEachron TA, Lu C, Paugh BS, Becksfort $\mathrm{J}$, et al. Somatic histone $\mathrm{H} 3$ alterations in pediatric diffuse intrinsic pontine gliomas and non-brainstem glioblastomas. Nat Genet. 2012;44(3):251-3.

39. Voso MT, D’Alo F, Greco M, Fabiani E, Criscuolo M, Migliara $\mathrm{G}$, et al. Epigenetic changes in therapy-related MDS/AML. Chem Biol Interact. 2010;184(1-2):46-9.

40. Tien HF, Tang JH, Tsay W, Liu MC, Lee FY, Wang CH, et al. Methylation of the p15(INK4B) gene in myelodysplastic syndrome: it can be detected early at diagnosis or during disease progression and is highly associated with leukaemic transformation. Br J Haematol. 2001;112(1):148-54.

41. Christiansen DH, Andersen MK, Pedersen-Bjergaard J. Methylation of p15INK4B is common, is associated with deletion of genes on chromosome arm $7 \mathrm{q}$ and predicts a poor prognosis in therapy-related myelodysplasia and acute myeloid leukemia. Leukemia. 2003;17(9):1813-9.

42. Quesnel B, Guillerm G, Vereecque R, Wattel E, Preudhomme C, Bauters F, et al. Methylation of the p15(INK4b) gene in myelodysplastic syndromes is frequent and acquired during disease progression. Blood. 1998;91(8):2985-90.

43. Shen L, Kantarjian H, Guo Y, Lin E, Shan J, Huang X, et al. DNA methylation predicts survival and response to therapy in patients with myelodysplastic syndromes. J Clin Oncol. 2010;28(4):605-13.

44. Toyota M, Ahuja N, Ohe-Toyota M, Herman JG, Baylin SB, Issa JP. CpG island methylator phenotype in colorectal cancer. Proc Natl Acad Sci USA. 1999;96(15):8681-6.

45. Noushmehr H, Weisenberger DJ, Diefes K, Phillips HS, Pujara K, Berman BP, et al. Identification of a $\mathrm{CpG}$ island methylator phenotype that defines a distinct subgroup of glioma. Cancer Cell. 2010;17(5):510-22.

46. Figueroa ME, Skrabanek L, Li Y, Jiemjit A, Fandy TE, Paietta E, et al. MDS and secondary AML display unique patterns and abundance of aberrant DNA methylation. Blood. 2009;114(16):3448-58.

47. Jiang Y, Dunbar A, Gondek LP, Mohan S, Rataul M, O'Keefe C, et al. Aberrant DNA methylation is a dominant mechanism in MDS progression to AML. Blood. 2009;113(6):1315-25.

48. Romermann D, Hasemeier B, Metzig K, Schlegelberger B, Langer $\mathrm{F}$, Kreipe $\mathrm{H}$, et al. Methylation status of LINE-1 sequences in patients with MDS or secondary AML. Verh Dtsch Ges Pathol. 2007;91:338-42.

49. Ko M, Huang Y, Jankowska AM, Pape UJ, Tahiliani M, Bandukwala HS, et al. Impaired hydroxylation of 5-methylcytosine in myeloid cancers with mutant TET2. Nature. 2010;468(7325):839-43.

50. Yamazaki J, Taby R, Vasanthakumar A, Macrae T, Ostler KR, Shen L, et al. Effects of TET2 mutations on DNA methylation in chronic myelomonocytic leukemia. Epigenetics. 2012;7(2):201-7.

51. Nikoloski G, van der Reijden BA, Jansen JH. Mutations in epigenetic regulators in myelodysplastic syndromes. Int J Hematol. 2012;95(1):8-16.

52. Kosmider O, Gelsi-Boyer V, Ciudad M, Racoeur C, Jooste V, Vey $\mathrm{N}$, et al. TET2 gene mutation is a frequent and adverse event in chronic myelomonocytic leukemia. Haematologica. 2009;94(12):1676-81.

53. Jankowska AM, Szpurka H, Tiu RV, Makishima H, Afable M, Huh J, et al. Loss of heterozygosity $4 \mathrm{q} 24$ and TET2 mutations associated with myelodysplastic/myeloproliferative neoplasms. Blood. 2009;113(25):6403-10.

54. Abdel-Wahab O, Mullally A, Hedvat C, Garcia-Manero G, Patel $\mathrm{J}$, Wadleigh M, et al. Genetic characterization of TET1, TET2, and TET3 alterations in myeloid malignancies. Blood. 2009;114(1):144-7.

55. Figueroa ME, Abdel-Wahab O, Lu C, Ward PS, Patel J, Shih A, et al. Leukemic IDH1 and IDH2 mutations result in a hypermethylation phenotype, disrupt TET2 function, and impair hematopoietic differentiation. Cancer Cell. 2010;18(6):553-67.

56. Moran-Crusio K, Reavie L, Shih A, Abdel-Wahab O, NdiayeLobry D, Lobry C, et al. Tet 2 loss leads to increased hematopoietic stem cell self-renewal and myeloid transformation. Cancer Cell. 2011;20(1):11-24.

57. Quivoron C, Couronne L, Della Valle V, Lopez CK, Plo I, Wagner-Ballon $\mathrm{O}$, et al. TET2 inactivation results in pleiotropic hematopoietic abnormalities in mouse and is a recurrent event during human lymphomagenesis. Cancer Cell. 2011;20(1):25-38.

58. Egger G, Liang GN, Aparicio A, Jones PA. Epigenetics in human disease and prospects for epigenetic therapy. Nature. 2004;429(6990):457-63. 
59. Issa JP, Kantarjian HM. Targeting DNA methylation. Clin Cancer Res. 2009;15(12):3938-46.

60. Yoo CB, Jones PA. Epigenetic therapy of cancer: past, present and future. Nat Rev Drug Discov. 2006;5(1):37-50.

61. Jones PA, Taylor SM. Cellular differentiation, cytidine analogs and DNA methylation. Cell. 1980;20(1):85-93.

62. Santini V, Kantarjian HM, Issa JP. Changes in DNA methylation in neoplasia: pathophysiology and therapeutic implications. Ann Intern Med. 2001;134(7):573-86.

63. Tsai HC, Li H, Van Neste L, Cai Y, Robert C, Rassool FV, et al. Transient low doses of DNA-demethylating agents exert durable antitumor effects on hematological and epithelial tumor cells. Cancer Cell. 2012;21(3):430-46.

64. Wijermans P, Lubbert M, Verhoef G, Bosly A, Ravoet C, Andre $\mathrm{M}$, et al. Low-dose 5-aza-2'-deoxycytidine, a DNA hypomethylating agent, for the treatment of high-risk myelodysplastic syndrome: a multicenter phase II study in elderly patients. J Clin Oncol. 2000;18(5):956-62.

65. Issa JP, Garcia-Manero G, Giles FJ, Mannari R, Thomas D, Faderl S, et al. Phase 1 study of low-dose prolonged exposure schedules of the hypomethylating agent 5-aza-2'-deoxycytidine (decitabine) in hematopoietic malignancies. Blood. 2004;103(5):1635-40.

66. Silverman LR, Demakos EP, Peterson BL, Kornblith AB, Holland JC, Odchimar-Reissig R, et al. Randomized controlled trial of azacitidine in patients with the myelodysplastic syndrome: a study of the cancer and leukemia group B. J Clin Oncol. 2002;20(10):2429-40.

67. Fenaux P, Mufti GJ, Hellstrom-Lindberg E, Santini V, Finelli C, Giagounidis A, et al. Efficacy of azacitidine compared with that of conventional care regimens in the treatment of higher-risk myelodysplastic syndromes: a randomised, open-label, phase III study. Lancet Oncol. 2009;10(3):223-32.

68. Kantarjian H, Issa JP, Rosenfeld CS, Bennett JM, Albitar M, DiPersio J, et al. Decitabine improves patient outcomes in myelodysplastic syndromes: results of a phase III randomized study. Cancer. 2006;106(8):1794-803.

69. Kantarjian H, Oki Y, Garcia-Manero G, Huang X, O'Brien S, Cortes J, et al. Results of a randomized study of 3 schedules of low-dose decitabine in higher-risk myelodysplastic syndrome and chronic myelomonocytic leukemia. Blood. 2007;109(1):52-7.

70. Oki Y, Jelinek J, Shen L, Kantarjian HM, Issa JP. Induction of hypomethylation and molecular response after decitabine therapy in patients with chronic myelomonocytic leukemia. Blood. 2008;111(4):2382-4.

71. Faderl S, Ravandi F, Huang X, Wang X, Jabbour E, GarciaManero G, et al. Clofarabine plus low-dose cytarabine followed by clofarabine plus low-dose cytarabine alternating with decitabine in acute myeloid leukemia frontline therapy for older patients. Cancer. 2012;118(18):4471-7.

72. Sekeres MA, List AF, Cuthbertson D, Paquette R, Ganetzky R, Latham D, et al. Phase I combination trial of lenalidomide and azacitidine in patients with higher-risk myelodysplastic syndromes. J Clin Oncol. 2010;28(13):2253-8.

73. Garcia-Manero G, Gore SD, Cogle C, Ward R, Shi T, Macbeth $\mathrm{KJ}$, et al. Phase I study of oral azacitidine in myelodysplastic syndromes, chronic myelomonocytic leukemia, and acute myeloid leukemia. J Clin Oncol. 2011;29(18):2521-7.

74. Datta J, Ghoshal K, Denny WA, Gamage SA, Brooke DG, Phiasivongsa $\mathrm{P}$, et al. A new class of quinoline-based DNA hypomethylating agents reactivates tumor suppressor genes by blocking DNA methyltransferase 1 activity and inducing its degradation. Cancer Res. 2009;69(10):4277-85.

75. Garcia-Manero G, Yang H, Bueso-Ramos C, Ferrajoli A, Cortes $\mathrm{J}$, Wierda WG, et al. Phase 1 study of the histone deacetylase inhibitor vorinostat (suberoylanilide hydroxamic acid [SAHA]) in patients with advanced leukemias and myelodysplastic syndromes. Blood. 2008;111(3):1060-6.

76. Raynal NJ, Si J, Taby RF, Gharibyan V, Ahmed S, Jelinek J, et al. DNA methylation does not stably lock gene expression but instead serves as a molecular mark for gene silencing memory. Cancer Res. 2012;72(5):1170-81.

77. Si J, Boumber YA, Shu J, Qin T, Ahmed S, He R, et al. Chromatin remodeling is required for gene reactivation after decitabine-mediated DNA hypomethylation. Cancer Res. 2010;70(17):6968-77.

78. Garcia-Manero G, Kantarjian HM, Sanchez-Gonzalez B, Yang H, Rosner G, Verstovsek S, et al. Phase 1/2 study of the combination of 5-aza-2'-deoxycytidine with valproic acid in patients with leukemia. Blood. 2006;108(10):3271-9.

79. Voso MT, Santini V, Finelli C, Musto P, Pogliani E, Angelucci E, et al. Valproic acid at therapeutic plasma levels may increase 5 -azacytidine efficacy in higher risk myelodysplastic syndromes. Clin Cancer Res. 2009;15(15):5002-7.

80. Kubicek S, O'Sullivan RJ, August EM, Hickey ER, Zhang Q, Teodoro ML, et al. Reversal of H3K9me2 by a small-molecule inhibitor for the G9a histone methyltransferase. Mol Cell. 2007;25(3):473-81.

81. Tan J, Yang X, Zhuang L, Jiang X, Chen W, Lee PL, et al. Pharmacologic disruption of Polycomb-repressive complex 2-mediated gene repression selectively induces apoptosis in cancer cells. Genes Dev. 2007;21(9):1050-63.

82. Kosmider O, Gelsi-Boyer V, Cheok M, Grabar S, Della-Valle V, Picard F, et al. TET2 mutation is an independent favorable prognostic factor in myelodysplastic syndromes (MDSs). Blood. 2009;114(15):3285-91.

83. Kosmider O, Gelsi-Boyer V, Slama L, Dreyfus F, Beyne-Rauzy $\mathrm{O}$, Quesnel B, et al. Mutations of IDH1 and IDH2 genes in early and accelerated phases of myelodysplastic syndromes and MDS/ myeloproliferative neoplasms. Leukemia. 2010;24(5):1094-6.

84. Walter MJ, Ding L, Shen D, Shao J, Grillot M, McLellan M, et al. Recurrent DNMT3A mutations in patients with myelodysplastic syndromes. Leukemia. 2011;25(7):1153-8.

85. Thol F, Friesen I, Damm F, Yun H, Weissinger EM, Krauter J, et al. Prognostic significance of ASXL1 mutations in patients with myelodysplastic syndromes. J Clin Oncol. 2011; 29(18):2499-506.

86. Bejar R, Levine R, Ebert BL. Unraveling the molecular pathophysiology of myelodysplastic syndromes. J Clin Oncol. 2011;29(5):504-15. 